\title{
Application of PI-Notch controller in the control of grid side converter to reduce PCC harmonic current for DFIG wind energy system
}

\author{
Ramon Rodrigues de Souza, Adson Bezerra Moreira, Paulo Sergio Nascimento Filho, Tárcio André dos Santos \\ Barros and Ernesto Ruppert Filho \\ LEPO/DSE/FEEC/UNICAMP \\ Rua João Pandiá Calógeras, 110 Campinas - SP (Brasil) \\ Phone/Fax number:+5519982 927461, e-mail: ramon.rodrigues11@yahoo.com.br, adsonbmoreira@gmail.com, \\ paulosnf@gmail.com, tarcioandre@hotmail.com and ruppert@fee.unicamp.br
}

\begin{abstract}
.
This work presents the analysis of harmonic of 5 th and 7 th orders impacts in the grid voltage in a wind generation system based on DFIG. Therefore, there were simulations of the active and reactive power control of the DFIG using the vector control by orientation of the magnetic stator flux.

The results of three simulations are presented. In the first simulation it is presented the analysis of the wind power generation system connected to an electric grid with purely sinusoidal voltage. In the second simulation, the wind generation system is connected to an electric grid with distorted voltage for 5th and 7th harmonic orders. In the third simulation it is shown the results of the reduction of harmonic distortion in the electrical currents at the PCC and at the output of the electronic power converter by applying notch filters in the converter current control loops connected to electrical grid.
\end{abstract}

\section{Key words}

Control design, vector control, wind power, doubly fed induction generator (DFIG) e distorted voltage.

\section{Introduction}

The generation of electricity from wind energy is growing in last years. In June 2014, the global wind capacity reached 336,327 MW [1]. According to the International Energy Agency (IEA), it is expected that by 2050 wind power will correspond to $18 \%$ of the world energy matrix, compared to $4 \%$ now [2].

Among the various types of electrical generators used to perform the conversion of mechanical energy into electric energy is the double-fed induction generator (DFIG). It is a robust generator that is usually employed in wind power generation systems. The stator terminals are connected directly to the grid, while the rotor circuit is connected to the electrical grid through a bidirectional AC/DC/AC power electronic converter. This power electronic converter is known in the literature as back-to-back. It takes no more than $30 \%$ of the total generator power decreasing the costs with power electronic converter [3]. Most of the studies related to the control of wind generation systems based in DFIG consider the system connection to the electrical grids with purely sinusoidal voltage, as is the case study presented in [4]-[5]. However, it is known that due to the presence of nonlinear loads in the electrical system waveforms of voltage and electric current may be distorted containing multiple frequencies of the fundamental. The IEEE Std. 519-1992 [6] is a very comprehensive document and it suggests studies related to the generation of harmonics, harmonic effects and methods of analysis and measurement with recommendations and their constraints are commonly used.

Several studies have assessed the behavior of electrical systems and connection of wind generation in its electric lines affected by harmonics. In [7] it is studied the control of a power electronic converter connected to the electric system with distorted voltage by harmonics of $5^{\text {th }}$ and $7^{\text {th }}$ orders.

In this study the behavior of a wind generation system based on DFIG is evaluated for the situation of connection to an electrical grid with voltage harmonic distortion with $5^{\text {th }}$ and $7^{\text {th }}$ order components by checking the negative impacts of these disturbances in the system.

The basic dynamic mathematical model of the DFIG is shown for purposes of controlling active and reactive powers of the machine, as well as the conventional control structures which use controllers of the proportional-integral type, by using the traditional method of the vector orientation of the stator magnetic flux .

Due to its simplicity it is used an L filter to make the converter interface with the power grid. To check the converter's behavior connected to the electric grid voltage contaminated with $5^{\text {th }}$ and $7^{\text {th }}$ harmonics orders it is deduced by the mathematical model of inductive filter and relationships of active and reactive instantaneous power.

The work concerns the analysis of the impacts of wind generation system due to the presence of harmonic components of 5th and 7th orders in the grid voltage. A proposal to reduce the negative impact due to the harmonic components in the electrical current measured at the point of common coupling (PCC) is also presented using a harmonic rejection technique that uses a PI 
controller cascaded with a notch filter configured to the frequency of $6 \omega_{s}$.

\section{Wind energy conversion system}

The simplified diagram of the wind energy conversion system is shown in Fig. 1. The system consists of the double-fed induction generator (DFIG), the wind turbine, the electric grid, an AC-DC-AC converter (also known as back-to-back) and the filter that connects the rotor converter to the grid. This topology allows bidirectional power flow in the rotor circuit, and allows speeds the generator to operate: sub synchronous, synchronous and super synchronous mode [9].

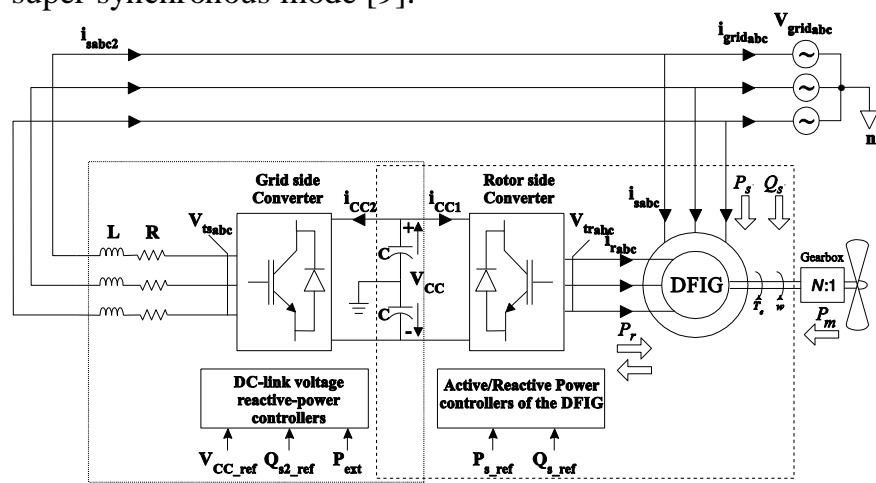

Fig 1. Illustrative representation of the wind generation system

\section{Active and reactive power control}

\section{A. DFIG model}

In this subsection the differential equations of the DFIG model are presented using space vector notation in the synchronous reference [10].

$$
\begin{aligned}
& \vec{v}_{d q s}=R_{S} \vec{\imath}_{d q s}+\frac{d \vec{\Psi}_{d q s}}{d t}+j \omega_{s} \vec{\Psi}_{d q s} \\
& \vec{v}_{d q r}=R_{r} \vec{\imath}_{d q r}+\frac{d \vec{\Psi}_{d q r}}{d t}+j \underbrace{\left(\omega_{S}-\omega_{m}\right)}_{\omega_{r}} \vec{\Psi}_{d q r} \\
& \vec{\Psi}_{d q s}=L_{s} \vec{\imath}_{d q s}+L_{m} \vec{\imath}_{d q r} \\
& \vec{\Psi}_{d q r}=L_{m} \vec{\imath}_{d q s}+L_{r} \vec{\imath}_{d q r}
\end{aligned}
$$

Where $v_{\mathrm{dqs}}$ e $\mathrm{v}_{\mathrm{dqr}}$ represent the voltages at the terminals of the stator and the rotor circuits, $\Psi_{\mathrm{dqs}}$ e $\Psi_{\mathrm{dqr}}$ representing the magnetic flux on the stator and rotor circuits, $i_{\text {dqs }}$ e $i_{d q r}$ represent the electrical currents at stator and rotor circuits, $R_{s}$ e $R_{r}$ represent the electrical resistances of the stator and rotor windings, $\mathrm{L}_{\mathrm{s}}$ e $\mathrm{L}_{\mathrm{r}}$ represent the leakage inductance of stator windings per-phase e $\mathrm{L}_{\mathrm{m}}$ is stator magnetizing inductance.

\section{B. Field Oriented}

According to the concept of the orientation of the magnetic flux the orientation according to the stator flux results in [11]-[12]:

$$
\vec{\psi}_{s, d q}=\psi_{s d}=\boldsymbol{\psi}_{s} \quad e \quad \psi_{s q}=0
$$

The final expressions of active and reactive power are presented in (3):

$$
\begin{aligned}
& P_{S}=-\frac{3}{2} v_{S} \frac{L_{M}}{L_{S}} i_{r q} \\
& Q_{S}=\frac{3}{2} \frac{L_{M}}{L_{S}} v_{S}\left(\frac{V_{S}}{\omega_{S} L_{M}}-i_{r d}\right)
\end{aligned}
$$

\section{Effect of the harmonic of the grid voltage effects on the grid side of the converter control}

\section{A. Grid side converter mathematical model}

Consider the schematic diagram shown in Fig. 1, where an inductive filter performs the interface between the power electronic converter and the electric grid. The dynamic equations of the system converter/filter/grid and the voltage at the DC bus in the synchronous reference frame are given by [8]:

$$
\begin{aligned}
& V^{+}{ }_{s d}=R\left(i^{+} d\right)+L \frac{d i^{+} d}{d t}-L \omega i^{+} q+V^{+} t d \\
& V^{+} s q=R\left(i^{+} q\right)+L \frac{d i^{+} q}{d t}+L \omega i^{+} d+V^{+} t q \\
& C \frac{d V_{D C}}{d t}=\frac{3}{2}\left(m^{+} d^{i^{+}} d+m^{+} q i^{+} q\right)-i_{\text {carga }}
\end{aligned}
$$

In the equations described in (4) the quantities involved can be rewritten in terms of the fundamental component and harmonic components of $5^{\text {th }}$ and $7^{\text {th }}$ orders as shown in the following equations [8]:

$$
\begin{gathered}
V^{+} d q=V^{+} d q_{+}+V^{+} d q 5_{-}+V^{+} d q 7+ \\
=V^{+} d q_{+}+{ }^{5-} d q 5_{-} e^{-j 6 \omega_{s} t}+V^{7+} d q 7_{+} e^{j 6 \omega_{s} t} \\
i^{+} d q=i^{+} d q_{+}+i^{+} d q 5_{-}+i^{+} d q 7+ \\
=i^{+} d q_{+}{ }^{+i^{5-}} d q 5_{-} e^{-j 6 \omega_{s} t}+i^{7+} d q 7_{+} e^{j 6 \omega_{s} t} \\
V^{+} t d q=V^{+} t d q_{+}+V^{+} t d q 5_{-}+V^{+} t d q 7+ \\
=V^{+} t d q_{+}+V^{5-} t d q 5_{-} e^{-j 6 \omega_{s} t}+V^{7+} t d q 7+e^{j 6 \omega_{s} t}
\end{gathered}
$$

Where, subscripts,+ 5 - and 7+ represent the positive sequence of the fundamental component and the harmonic components of $-5 \omega_{\mathrm{s}}$ and $7 \omega_{\mathrm{s}}$, respectively.

Substituting (5) in (4), yelds the dynamic equations of the system converter/filter/grid as function of $5^{\text {th }}$ and $7^{\text {th }}$ orders components.

The relationship between active power and reactive power is given by [8]:

$$
\begin{gathered}
P+j Q=\frac{3}{2} \vec{v}^{+} d q \vec{\imath}^{+*} d q \\
=\frac{3}{2}\left[V^{+} d q_{+} e^{j \omega_{s} t}+V^{5-} d q 5-e^{-j 5 \omega_{s} t}+V^{7+} d q 7+e^{j 7 \omega_{s} t}\right] . \\
{\left[i^{+} d q_{+} e^{-j \omega_{s} t}+i^{5-} d q 5{ }_{-} e^{j 5 \omega_{s} t}+i^{7+} d q 7+e^{-j 7 \omega_{s} t}\right]}
\end{gathered}
$$

Where, 


$$
\begin{aligned}
& P=P_{0}+P_{\text {cos } 6} \cos \left(6 \omega_{s} t\right)+P_{\text {sen }} \sigma^{\operatorname{sen}\left(6 \omega_{s} t\right)} \\
& +P_{\cos 12 \cos \left(12 \omega_{s} t\right)+P_{\operatorname{sen} 12} \operatorname{sen}\left(12 \omega_{s} t\right)} \\
& Q=Q_{0}+Q_{\cos 6} \cos \left(6 \omega_{s} t\right)+Q_{\operatorname{sen} 6} \operatorname{sen}\left(6 \omega_{s} t\right)
\end{aligned}
$$

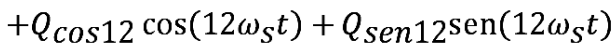

It can be seen that the power components pulsating at the frequency $6 \omega_{\mathrm{s}}$, i. e. Pcos6, Psen6, Qcos6 and Qsen6, are produced by the interaction of the fundamental and harmonic electromagnetic quantities, while the components pulsating at the frequency $12 \omega_{\mathrm{s}}$ are produced by the interaction of the $5^{\text {th }}$ and $7^{\text {th }}$ harmonic electromagnetic quantities

\section{B. Reducing the impact of harmonic distortion in the grid voltage on the electrical current control of the grid side converter}

Fig. 2 shows the control loop of the direct-axis electric current and the quadrature axis, in which notch filters were added. With the addition of this transfer function in the control loop becomes necessary to remake the design of the PI controller gains used in the conventional control.

a)

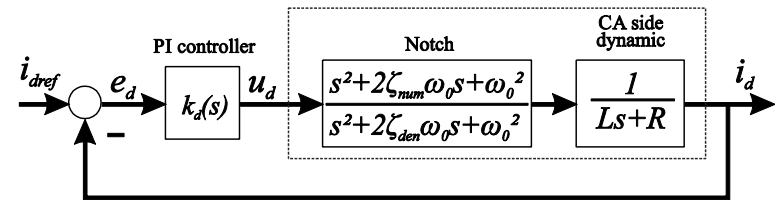

b)

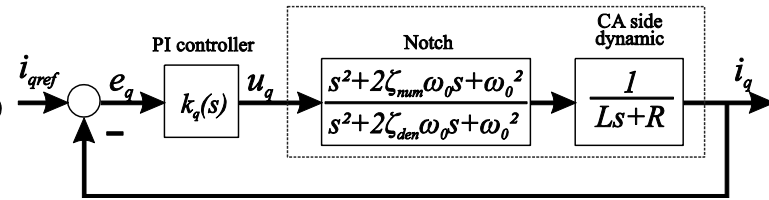

Fig. 2. Grid side converter current control loop. a) direct axis current. b) quadrature axis current.

The addition of the notch filter transfer function of the current control loop changes the dynamic response of the system. Therefore, the method is adopted of increased plant, wherein the notch filter transfer function is designed and then placed in cascade with the dynamic filter L. The PI controller is designed by the frequency response method [13]-[14].

The notch filter transfer function is given by (8).

$$
F N(s)=\frac{s^{2}+2 \omega_{0} \zeta_{n u m} s+\left(\omega_{0}\right)^{2}}{s^{2}+2 \omega_{0} \zeta_{d e n} s+\left(\omega_{0}\right)^{2}}
$$

Where $\omega_{0}=2 \pi f_{0}$ e $f_{0}=n f, n$ is the component order e $f$ the rated frequency.

The resonant frequency must be selected of the filter and the gain of the resonance frequency. As the harmonic components of $5^{\text {th }}$ and $7^{\text {th }}$ orders present in the grid voltage insert 6th order disturbances in the current control loop of the power electronic converter [15], the notch filter is set to reject disturbances in the frequency of $360 \mathrm{~Hz}$.

The value of the resonance peak is obtained from the ratio between the coefficients $\zeta_{\text {num }}$ and $\zeta_{\text {den }}$ :

$$
\zeta_{\text {num }}=10^{\frac{M t}{20}} \zeta_{\text {den }}
$$

Fig. 3 presents the frequency response of current control open loop of grid side converter for different $\mathrm{Kp}$ and $\mathrm{Ki}$ values. The notch filter was set to reject the $6^{\text {th }}$ order component, with the peak resonance set for a gain of $100 \mathrm{~dB}$ at $360 \mathrm{~Hz}$.

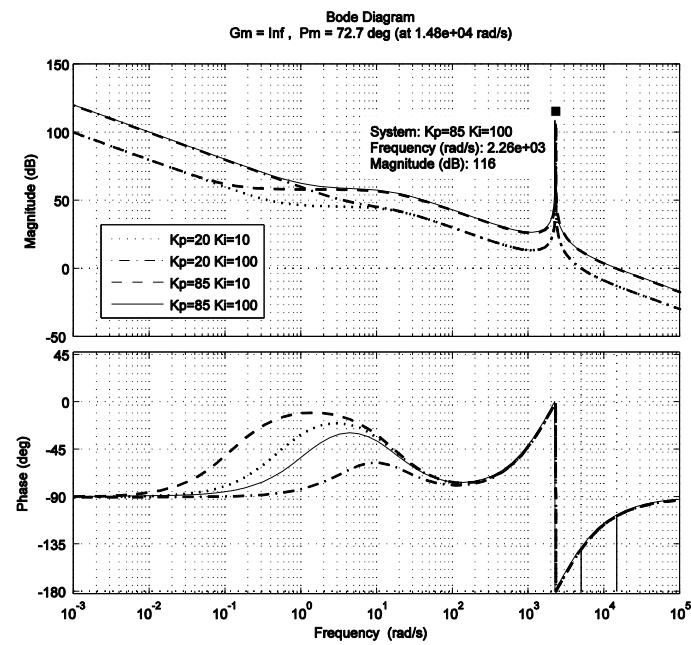

Fig. 3. Frequency response of the current control loop of the grid side converter with notch filter

\section{Simulation results}

\section{Simulation 1}

For the simulation 1 it is considered that wind system is connected to the power grid with sinusoidal voltage as shown in Fig. 4a). The amplitude of the voltage is $180 \mathrm{~V}$ and the rated frequency is $60 \mathrm{~Hz}$. The values of the parameters used in the simulation of the wind system are shown below:

DFIG rated power: $2.25 \mathrm{~kW}$

4 poles, $60 \mathrm{~Hz}, 220 \mathrm{~V}, \mathrm{pf}=1.00$

$\mathrm{N}_{\mathrm{n}}=1730 \mathrm{rpm} ; \mathrm{J}=0.05 \mathrm{Kg} \cdot \mathrm{m}^{2}$

$\mathrm{R}_{\mathrm{s}}=1,67 \Omega ; \mathrm{R}_{\mathrm{r}}=2,2 \Omega$

$\mathrm{L}_{\mathrm{s}}=0.1665 \mathrm{H} ; \mathrm{L}_{\mathrm{r}}=0.1665 \mathrm{H} \mathrm{e} \mathrm{L}_{\mathrm{m}}=0.0829 \mathrm{H}$

DC-Bus Capacitance: $\mathrm{C}=3500 \mu \mathrm{F}$

DC-Bus Voltage: $\mathrm{V}_{\mathrm{DC}}=410 \mathrm{~V}$

Switching frequency: $15 \mathrm{kHz}$

$\mathrm{L}=20 \mathrm{mH} ; \mathrm{R}=0.1 \Omega$

Fig. $4 \mathrm{~b}$ it can be observed the DC bus voltage behavior. The dynamic of the DC bus voltage presents an overshoot (maximum value of $420.25 \mathrm{~V}$ ) stabilizing at the desired value of $410 \mathrm{~V}$ in $0.8 \mathrm{~s}$. In $1.2 \mathrm{~s}$ when the speed ramp starts there is a small overvoltage corresponding to a transition time that start to finish at $1.4 \mathrm{~s}$ so returning to the constant value (steady state).

A step of active power of $2 \mathrm{~kW}$ is applied at the instant $0.5 \mathrm{~s}$ and this active power sent to the electric grid by the three phase stator terminals. The dynamic response of the active power control corresponds to the step response of a first-order plant achieving the steady state in approximately $0.7 \mathrm{~s}$. Reactive power is maintained at zero, because it is desired to operate with unity power 
factor. Comparing to the results presented in [9], the results obtained here are satisfactory.

The electromagnetic torque and the shaft torque have opposite directions which tend to balance according to the acceleration of the system axis. In this work the negative electromagnetic torque means that the electrical machine is operating as a generator, as shown in Fig. 4e.

a)

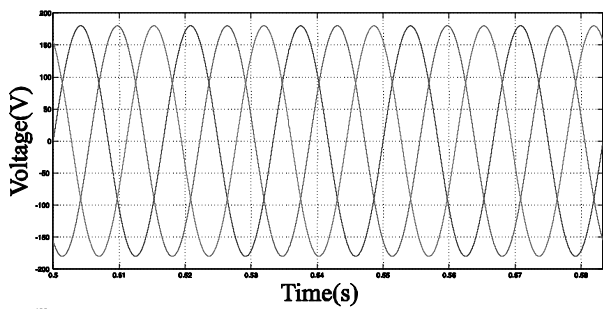

b)
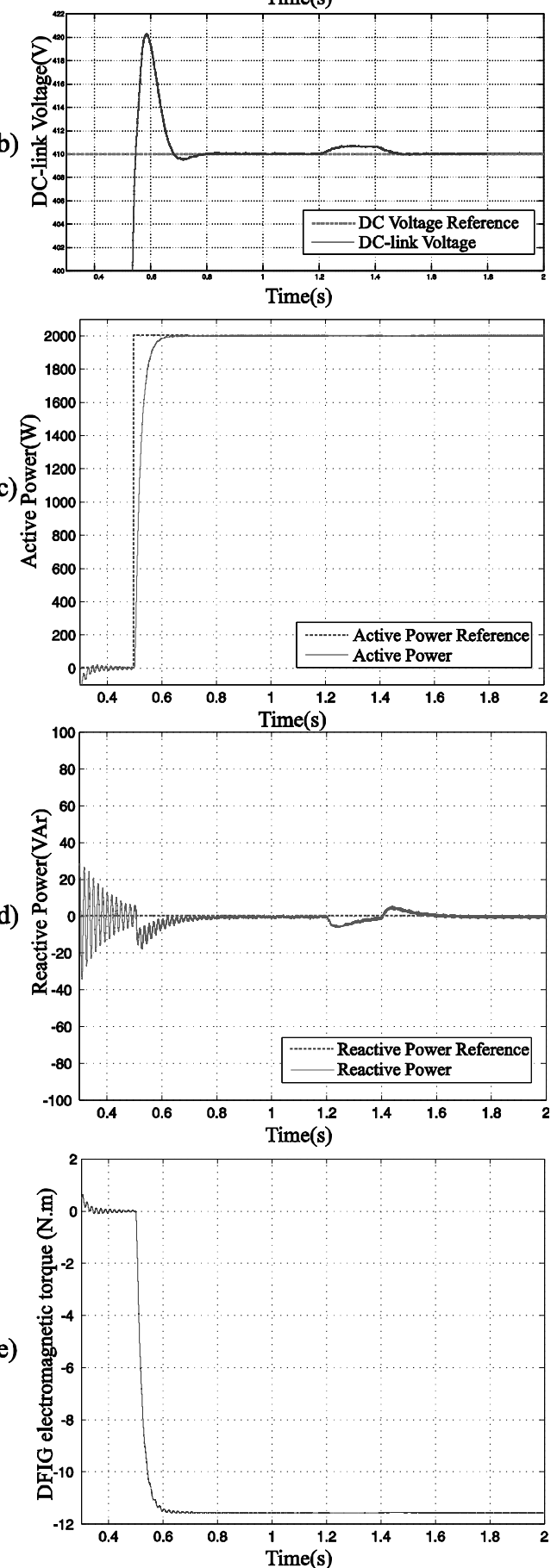

Fig. 4. a) PCC voltage, b) DC-Bus voltage, c) Active power, d) Reactive power, e) Electromagnetic torque

\section{Simulation 2}

The voltage waveform of the electrical network showing the presence of $5^{\text {th }}$ and $7^{\text {th }}$ harmonics is shown in Fig. 5a, its estimated total harmonic distortion is $9.90 \%$.

The active and reactive power have components that make them pulsating specifically in frequencies of 6th and 12th orders, as in [8]. In Figure 5c it is shown the dynamic response of the active power in which one can see that, despite the desired reference being followed it, presents distortion in form of small oscillations. In Fig. $5 \mathrm{~d}$ it can be shown the dynamic response of reactive power, in which there has been a sine behavior that may result in fluctuations in the power factor that was configured to work as a unit.

The electromagnetic torque of the DFIG also shows oscillatory behavior, being shown in Fig. 5e.

\section{Simulation 3}

In the simulation 3 it is proposed to reduce the distortions in the electrical current in the output of the power electronic converter and the electrical current measured at the PCC due to the introduction of notch filters that reject 6th order disturbances in the electric current control loops in the grid side converter.

Through the Tables 1 and 2 it is possible to make a quantitative analysis of electrical current distortions, in which the values are compared to the situation of without notch filter and with notch filter. The percentage of 5th and 7 th orders components are presented in addition to the total harmonic distortion of the electrical currents in the output of power electronic converter and the PCC. The introduction of a filter is able to reject 6th order component can reduce the impacts of the $5^{\text {th }}$ order component with negative sequence and the $7^{\text {th }}$ order component with positive sequence as presented [16].

In Fig. 6a it can may be observed less distortion in the electrical currents measured at the output of electronic converter and PCC, respectively.

Table 1 - Percentage of 5th and 7th harmonics and THD in the electrical current measured at the output of the converter without notch filter and with notch filter.

\begin{tabular}{ccc}
\hline & No Notch Filter & With Notch Filter \\
\hline $5^{\text {th }}$ & $1.37 \%$ & $0.2 \%$ \\
\hline $7^{\text {th }}$ & $1.80 \%$ & $0.11 \%$ \\
\hline THD & $2.42 \%$ & $0.88 \%$ \\
\hline
\end{tabular}

Table 2 - Percentage of 5th and 7th harmonic orders and the THD in the electrical current measured at the PCC without notch filter and with notch filter.

\begin{tabular}{ccc}
\hline & No Notch Filter & With Notch Filter \\
\hline $5^{\text {th }}$ & $3.88 \%$ & $0.42 \%$ \\
\hline $7^{\text {th }}$ & $5.30 \%$ & $0.39 \%$ \\
\hline THD & $7.00 \%$ & $2.44 \%$ \\
\hline
\end{tabular}


a)

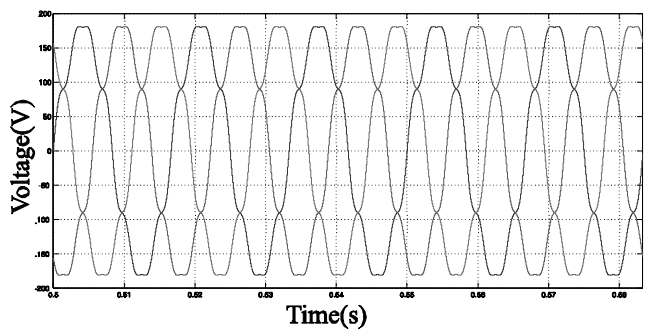

b)

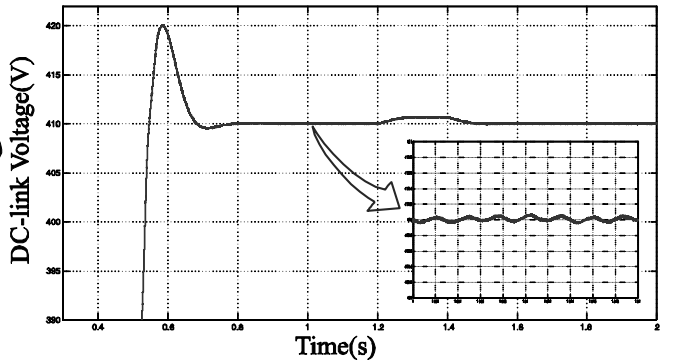

c)

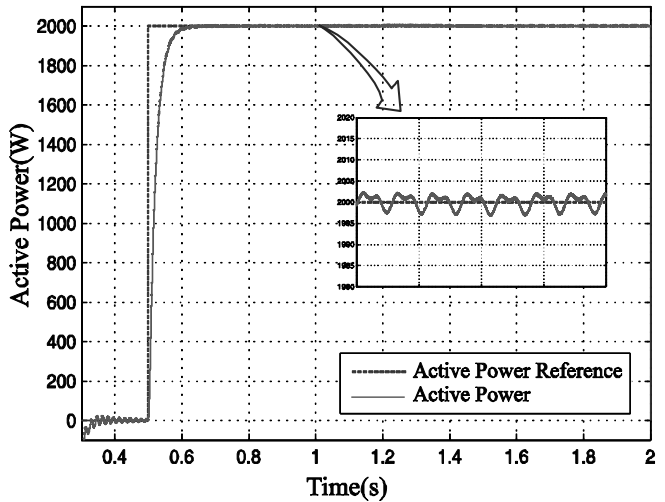

d)

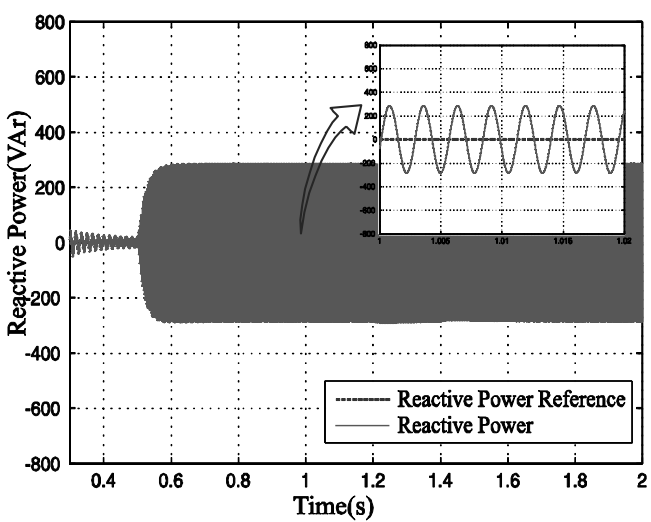

e)

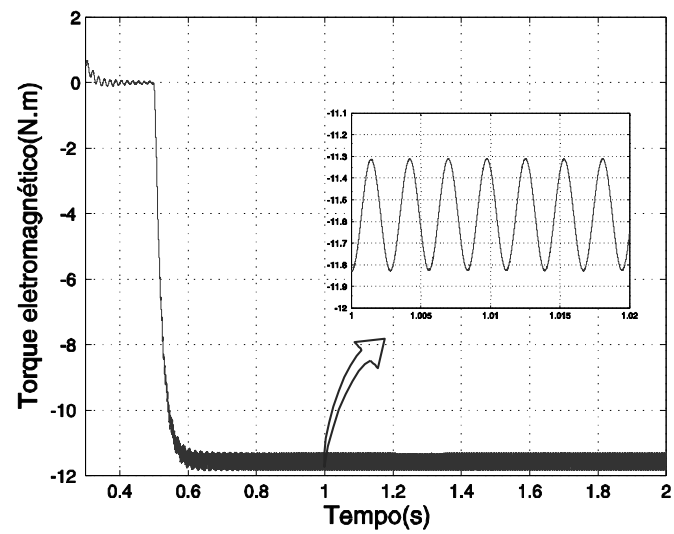

Fig. 5. a) PCC voltage with harmonics components $5^{\text {th }}$ and $7^{\text {th }}$ orders b) DC-Bus voltage c) Active power d) Reactive power and e) Electromagnetic torque a)

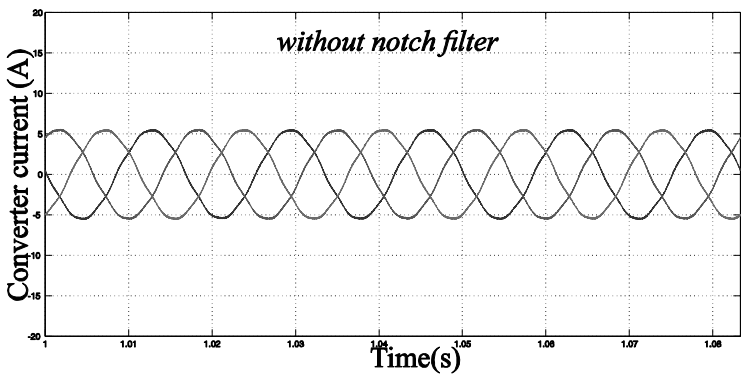

b)

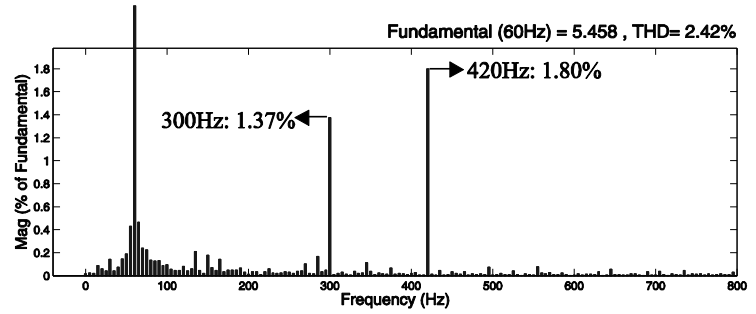

c)

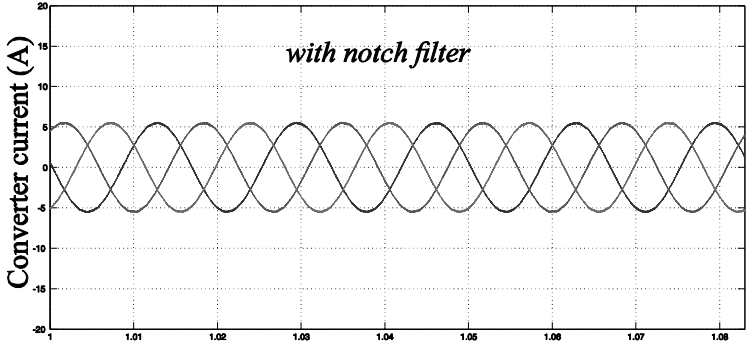

d)

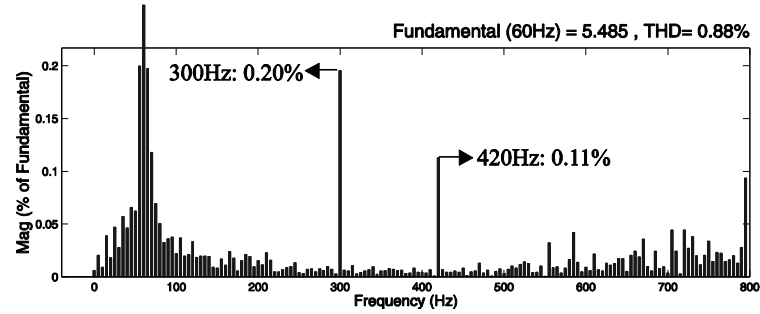

Fig. 6. a) Electric current in the VSC output without notch filter b) Spectrum amplitudes of the output electric current VSC without notch filter c) Electric current to the VSC output with notch filter b) Spectrum amplitudes of the output electric current VSC with notch filter.

\section{Conclusion}

In this work it was presented the active and reactive power control through technical orientation of the stator magnetic flux of the doubly-fed induction generator connected to the grid, in which it was used a back-toback PWM converter.

The presence of components of $5^{\text {th }}$ order with negative sequence and $7^{\text {th }}$ order with positive sequence in the grid voltage, shown in simulation 2 , causes fluctuations in real and reactive power in the frequencies of $6 \omega \mathrm{s}$ and $12 \omega \mathrm{s}$, and increase the distortion of electric current in the PCC.

To reduce distortions in the electrical current measured at the output of electronic converter and the PCC it was used a $6^{\text {th }}$ order notch filter cascaded connected with the PI controller in the electric current loop of the grid side converter. Due to the disturbance rejection behavior in the frequency of $360 \mathrm{~Hz}$, the introduction of the notch filter in the control system contributed to the reduction of distortions of electric current. 
a)

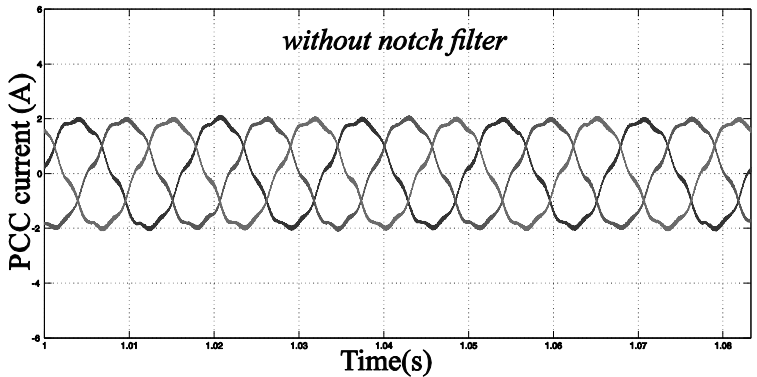

b)

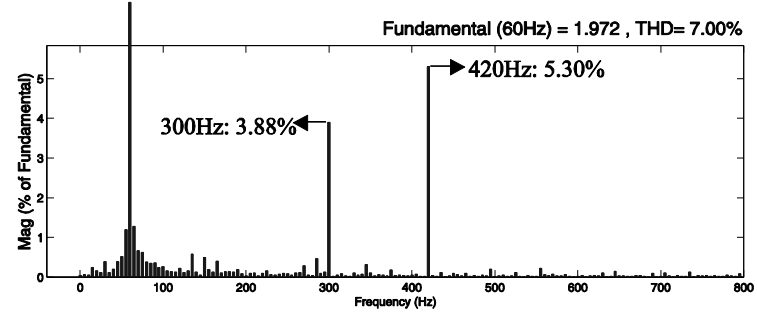

c)
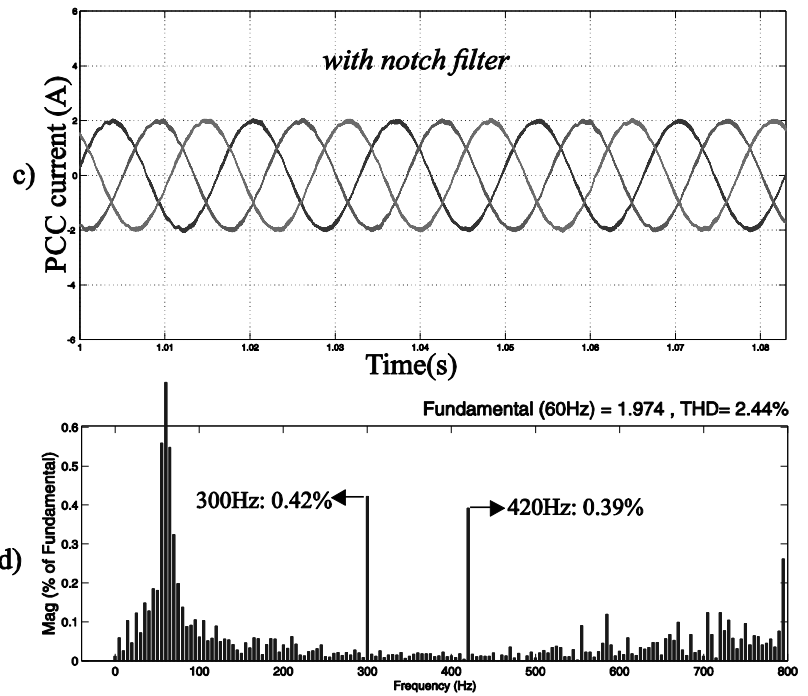

Fig. 7. a) PCC electric current without notch filter b) PCC Electric current spectrum without notch filter c) PCC electric current with notch filter d) PCC Electric current frequency spectrum with notch filter

\section{Acknowledgement}

FAPEAM and CPFL for the financial support of this research.

\section{References}

[1] THE WORLD WIND ENERGY ASSOCIATION (Org.). "Half-year Report: 2014". Available: www.wwindea.org Access: 06 oct. 2014.

[2] INTERNACIONAL ENERGY AGENCY (Paris) (Org.). “Technology Roadmap: Wind energy”. 2013. Available: www.iea.org. Access em: 06 out. 2014.

[3] SGUAREZI FILHO, Alfeu Joãozinho. "Controle de potências ativa e reativa de geradores de indução trifásicos de rotor bobinado para aplicação em geração eólica com a utilização de controladores baseados no modelo matemático dinâmico do gerador”. 132 f. Tese (Doutorado) - UNICAMP, Campinas, 2010.
[4] ABAD, G. et al. "Doubly Fed Induction Machine: MODELING AND CONTROL FOR WIND ENERGY GENERATION”. Nova Jersey: John Wiley \& Sons, 2011. 633p. [5] AGUIAR JUNIOR, E. A., “Análise Básica de operação do gerador de dupla alimentação para aproveitamento eólico”. 98 f. Dissertação (Mestrado), UFRJ, Rio de Janeiro, 2007.

[6] IEEE Std 519-522, “IEEE Recommended Practices and Requirements for harmonic Control in Electrical Power Systems", Abril/1993, New York/USA.

[7] L., Changijin et al. "Stator current harmonic control with resonant controller for doubly fed induction generator”. IEEE Trans. On Power Electronics, China, v. 27, n. 7, p.3207-3220, jul. 2012.

[8] NIAN, Heng; QUAN, Yu; HU, Jiabing. “Improved control strategy of DFIG-based wind power generation systems connected to a harmonically polluted network". Electric Power Systems Research, China, v. 86, p.85-97, 4 jan. 2012.

[9] YAZDANI, Amirnaser; IRAVANI, Reza. "VoltageSourced Converters in Power Systems: Modeling, Control and Aplications". Nova Jersey: John Wiley \& Sons, 2010. 473 p.

[10] BIM, Edson. "Máquinas Elétricas e Acionamento". 2. ed. Campinas: Unicamp, 2002. 568 p.

[11] PENA, R.; CLARE, J. C.; ASHER, G. M.. "Double Fed Induction Generator Using Back-to-back PWM Converters and its Application to Variable-speed Wind-energy Generation”. Proceedings Electric Power Application, Sp, v. 143, n. 3, p.231-241, 1996.

[12] TRINDADE, Filipe Sarmento. "Estudo do Controle de Potências Ativa e Reativa de Geradores de Indução Duplamente Alimentados com Aplicação na Geração Eólica”. Dissertação (Mestrado) UNICAMP, Campinas, 2013.

[13] OGATA, Katsuhiko. "Engenharia de Controle Moderno”. 4. ed. São Paulo: Prentice Hall, 2003.

[14] DORF, R C; BISHOP, R H. "Sistemas de Controle Modernos”. 8. ed. Rio de Janeiro: Ltc, 2001. 659 p

[15] PIERCE, Seth J., "Reducing stator current harmonics for a doubly-fed induction generator connected to a distorted grid”. 73 f. Dissertação (Mestrado), Naval Postgraduate School, Monterey, 2013.

[16] QUAN, Y., et. al., "Improved Control of the Gridconnected Converter under the Harmonically Distorted Grid Voltage Conditions", College of Electrical Engineering, Zhejiang University, China, 2011. 